\title{
Best Paper Awards for 2018
}

During 2013, Birkhäuser (Springer) instituted three Best Paper Awards for papers published in Circuits, Systems and Signal Processing (see the announcement in the October 2013 issue of CSSP). A call for nominations for these awards was sent out to all the Associate Editors inviting them to nominate those papers published in 2017 or 2018 in CSSP, which should be considered for these awards. This call was also posted on the CSSP Website. A total of six papers were nominated. A Selection Committee consisting of Dr. Raj Senani, Netaji Subhas University of Technology, New Delhi, India; Dr. Byung-Gyu Kim, SunMoon University, Chungnam, Republic of Korea and Dr. Huawei Chen, Nanjing University of Aeronautics and Astronautics, Nanjing, China was set up to select the best paper in each category for the year 2018. The recipients for the Armen H. Zemanian Best Paper Award given for the best paper published in 2018 in the areas of Circuits and Systems are Stravroula Kapoulea, Costas Psychalinos and Ahmed S. Elwakil for the paper entitled "Minimization of Spread of Time Constants and scaling Factors in Fractional Order Differentiator and Integrator Realizations", published in the December 2108 issue, pp. 5647-5663. The recipients for the Sydney $R$. Parker Best Paper Award given for the best paper published in 2018 in the area of Signal Processing are Abhishek Choubey and Basant Kumar Mohanty for their paper entitled "Novel Data Access Scheme and Efficient Parallel Architecture for Multilevel 2-D DWT", published in the October 2018 issue, pp. 4482-4503. The latter paper was also chosen for the M.N.S. Swamy Best Paper Award, which is given for the best paper published in 2017 or 2018 irrespective of the subject area. Each of these awardees will receive a certificate and a cash prize. I would like to congratulate the recipients of the three awards. I would also like to take this opportunity to thank all the nominators and, especially, the members of the Selection Committee for their time and effort in selecting the winners for the various awards.

\section{M.N.S. Swamy \\ Editor-in-Chief, CSSP}

Publisher's Note Springer Nature remains neutral with regard to jurisdictional claims in published maps and institutional affiliations. 